
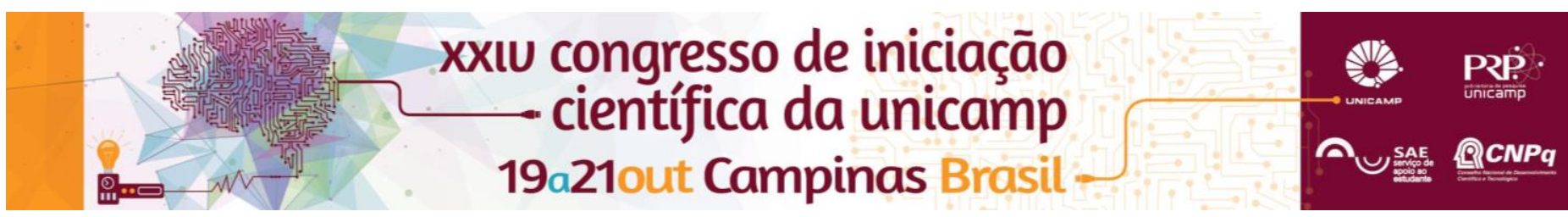

\title{
Análise numérica de vibração de uma viga com grandes deformações.
}

\section{Rhenan F. H. Garcia*.}

\section{Resumo}

Com o objetivo de reduzir a massa de manipuladores robóticos atuais sem gerar aumento vibracional em suas extremidades, propomos neste projeto aumentar a velocidade de atuação sem prejudicar a precisão dos movimentos, buscando estudar e atualizar um modelo que represente a estrutura de um manipulador robótico flexível acionado por tendões. Este, por possuir menor massa e rigidez quando comparado com manipuladores atuais, apresenta uma maior dificuldade em controlar as vibrações decorrentes dessas condições. Dessa forma, desenvolveu-se um modelo através de simulação numérica pelo método dos elementos finitos (MEF) e validação com a literatura disponível, que represente as grandes deformações e vibrações sofridas por esse tipo de manipulador, compreendendo de forma mais realista seu comportamento.

\section{Palavras-chave:}

Simulação numérica, manipuladores robóticos, vibração.

\section{Introdução}

Atualmente, os manipuladores robóticos priorizam a maximização da rigidez, objetivando 0 aumento da precisão de suas ações através da redução vibracional que ocorre nas extremidades, contudo o cumprimento desse objetivo exige que esses manipuladores possuam grande massa e, por consequência, menor velocidade de atuação.

Em contraste aos manipuladores mencionados, existem aqueles com braços flexíveis e menor massa. Entretanto essa redução de massa, reduz, também, sua rigidez, produzindo um efeito indesejado: vibrações.

Nesse cenário, este projeto busca apresentar um modelo que descreva a atuação de manipuladores flexíveis acionados por tendões.

\section{Resultados e Discussão}

A partir do segmento de estudos da área espacial, em que a massa se torna uma restrição, desenvolve-se o conceito de combinar cabos a vigas, que, aliados a tendões, permite a construção de estruturas pré-tensionadas com uma certa rigidez, possibilitando a redução vibracional nas extremidades ao deformar suas geometrias.

Estruturas sob deformações lineares e não lineares podem ser analisadas através de simulações numéricas com base no método dos elementos finitos. Com este fim, após alguns testes, escolheu-se software ANSYS 16.0 (ANSYS Mechanical APDL), para obter um modelo que representasse estática e dinamicamente a estrutura, comparando-o, a fim de validação, com a literatura, como demonstram as figuras 01 e 02 :

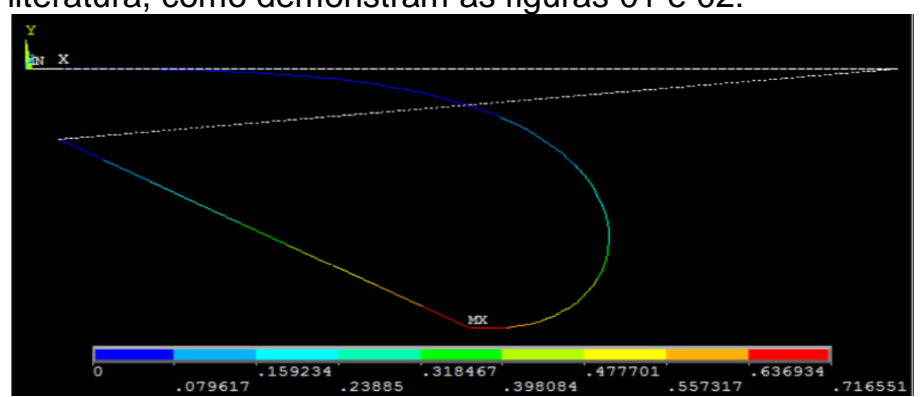

Figura 01. Deformação da estrutura no ANSYS Mechanical APDL.

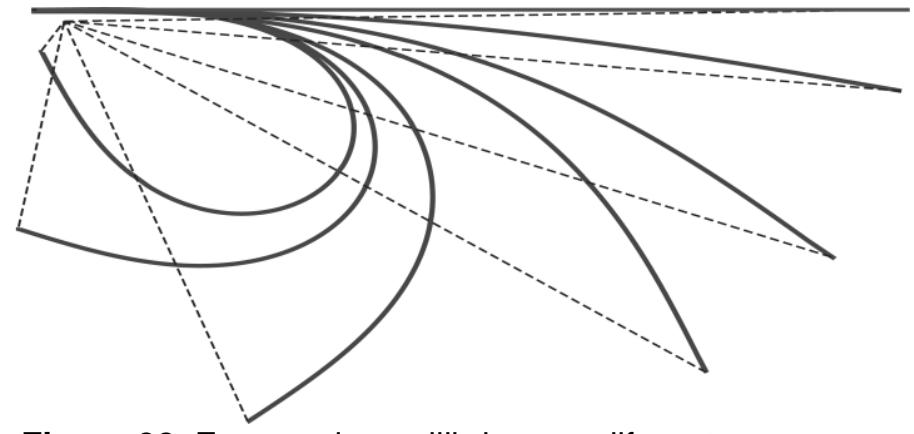

Figura 02. Formas de equilibrio para diferentes cargas apresentadas por Holland et all (2006).

\section{Conclusões}

O projeto permitiu ao aluno ampliar suas habilidades alinhadas as pesquisas acadêmicas, permitindo-o desenvolver, através de simulações numéricas por software comercial, um modelo simplificado de um manipulador robótico flexível acionado por tendões, buscando representar seu comportamento de atuação.

\section{Agradecimentos}

A CNPq pelo apoio financeiro fornecido.

${ }^{1}$ FRISCH -FAY, R. Flexible Bars. London Butterworths, 1962.

${ }^{2}$ HOLLAND, D.B., STANCIULESCU, I., VIRGIN, L.N., and PLAUT, R.H. Vibration and large deflection of cantilevered elastica compressed by angled cable, AIAA Journal, Vol. 44, 2006, pp.1468-1476.

${ }^{4}$ IZUKA, Jaime Hideo, Modelo e teste experimental para o controle de vibração de vigas longas deformadas, 2014. Tese (doutorado) - Faculdade de Engenharia Mecânica, Universidade Estadual de Campinas, Campinas, 2014.

5 TIMOSHENKO, S.P.; GERE, J.M. Theory of Elastic Stability, 2sd ed., McGraw-Hill, 1961.

${ }^{6}$ Yau, J. D., Close-form solutions of large deflections for a guyed cantilever column pulled by an inclinations cable, Journal of Marine Science and Technology, Vol. 18, No. 1, 2010, pp. 130-136. 